\title{
DECLINE IN HOSPITALIZATION TREND FOR CARDIOVASCULAR DISEASES SENSITIVE TO PRIMARY HEALTHCARE
}

\author{
Maicon Henrique Lentsck ${ }^{1}$, Ana Claudia Saito², Thais Aidar de Freitas Mathias ${ }^{3}$
}

\footnotetext{
${ }^{1}$ Doctoral student in Post-graduate Nursing Program, Nursing. Universidade Estadual de Maringá (UEM). Maringá, Paraná, Brazil. E-mail: maiconlentsck@yahoo.com.br

2 Nursing Graduate UEM. Maringá, Paraná, Brazil. E-mail: acsaito@hotmail.com

${ }^{3}$ Ph.D. in Public Health. Professor, Nursing Department, Post-graduate Nursing Program, UEM. Maringá, Paraná, Brazil. E-mail: tafmathias@gmail.com
}

\begin{abstract}
Objective: was to analyze the trend of hospitalizations for cardiovascular conditions sensitive to primary healthcare from 2000 to 2011. Method: an ecological study of the tendency of hospitalization rates for cardiovascular diseases by residence, aged between 35 and 74 years, according to the main diagnoses of hospitalization, gender and age, with data from the Hospital Information System of the Brazilian National Unified Health System (Sistema de Informações Hospitalares do Sistema Único de Saúde) and using polynomial regression models.

Results: an average annual decline of 5.6 per 10,000 inhabitants $\left(r^{2}=0.9 ; p<0.001\right)$ of hospitalization rates by cardiovascular diseases was observed. Decreasing trends for hypertension, heart failure and cerebrovascular diseases were also identified, while hospitalization rates by angina remained stable. The decrease in admission rates due to cardiovascular conditions was similar between both genders, although these rates were higher for men aged 55 to 74 years.

Conclusion: the decline in hospitalization rates for primary care-sensitive cardiovascular diseases indicates, in addition to other factors, improved access and quality of primary healthcare actions, especially for residents aged 55-74 years, and also for women whose decline was more pronounced. The health team should implement actions to prevent chronic disease complications, and consequently hospitalizations for men and for angina, in order to eliminate health disparities.
\end{abstract}

DESCRIPTORS: Cardiovascular diseases. Primary health care. Hospitalization. Time series studies. Health services evaluation.

\section{TENDÊNCIA DE DECLÍNIO DAS HOSPITALIZAÇÕES POR DOENÇAS CARDIOVASCULARES SENSÍVEIS À ATENÇÃO PRIMÁRIA}

\section{RESUMO}

Objetivo: analisar a tendência das internações por condições cardiovasculares sensíveis à atenção primária, de 2000 a 2011.

Método: estudo ecológico da tendência das taxas de internação por doenças cardiovasculares, por residência, entre 35 e 74 anos, segundo diagnóstico principal de internação, sexo e idade, com dados do Sistema de Informações Hospitalares do Sistema Único de Saúde e utilização de modelos de regressão polinomial.

Resultados: houve declínio médio anual de 5,6 por 10.000 habitantes $\left(\mathrm{r}^{2}=0,9 ; p<0,001\right)$ das taxas de internação por doenças cardiovasculares. Tendência descrecente também foi identificada para hipertensão, insuficiência cardíaca e doenças cerebrovasculares, enquanto as taxas de internação por angina permaneceram estáveis. O decréscimo das taxas de internação por condições cardiovasculares foi semelhante entre os sexos, embora esses índices sejam mais elevadas para homens de 55 a 74 anos.

Conclusão: o declínio das taxas de internação por doenças cardiovasculares sensíveis à atenção primária indica, além de outros fatores, melhora no acesso e qualidade das ações da atenção primária, principalmente para residentes de 55 a 74 anos, e também para as mulheres cujo declínio foi mais acentuado. A equipe de saúde deve implementar ações de prevenção das complicações das doenças crônicas e, consequentemente, das internações para o sexo masculino e para a angina, para eliminar disparidades de saúde.

DESCRITORES: Doenças cardiovasculares. Atenção primária à saúde. Hospitalização. Estudos de séries temporais. Avaliação de serviços de saúde. 


\title{
TENDENCIA DE LA DISMINUCIÓN DE LAS TASAS DE HOSPITALIZACIÓN DE ENFERMEDADES CARDIOVASCULARES SENSIBLES A LA SALUD PRIMARIA
}

\begin{abstract}
RESUMEN
Objetivo: analizar la evolución de las hospitalizaciones por condiciones cardiovasculares sensibles a la atención primaria de salud de 2000 a 2011.

Metodo: estudio ecológico de la tendencia de las tasas de hospitalización por enfermedades cardiovasculares por residencia, entre 35 y 74 años, segundo diagnósticos de hospitalización, género y edad, con datos del Sistema de Información Hospitalaria del Sistema Único de Saúde y utilizando modelos de regresión polinomial.

Resultados: se observó una disminución media anual de 5,6 por 10.000 habitantes ( $\mathrm{r} 2=0,9$, p <0,001) de las tasas de hospitalización por enfermedades cardiovasculares. También se identificaron tendencias decrecientes para hipertensión, insuficiencia cardíaca y enfermedades cerebrovasculares, mientras que las tasas de hospitalización por angina se mantuvieron estables.

Conclusión: la disminución de las tasas de admisión por condiciones cardiovasculares fue similar entre ambos géneros, aunque estas tasas fueron mayores para los hombres de 55 a 74 años. La disminución de las tasas de hospitalización de las enfermedades cardiovasculares de atención primaria indica, además de otros factores, un mejor acceso y calidad de las acciones de atención primaria, especialmente para los residentes de 55-74 años, y también para las mujeres cuyo descenso fue más pronunciado. El equipo de salud debe implementar acciones para prevenir las complicaciones de las enfermedades crónicas y, en consecuencia, las hospitalizaciones para hombres y para la angina, con el fin de eliminar las disparidades en la salud.
\end{abstract}

DESCRIPTORES: Enfermedades cardiovasculares. Atención primaria de salud. Hospitalización. Estudios de series temporales. Evaluación de servicios de salud.

\section{INTRODUCTION}

Cardiovascular diseases (CVDs) are the main cause of death worldwide, and their impact on the population's health and quality of life is also noticed in hospitalizations, which even with a decline in the 2000s, remains among the main causes of hospitalizations. ${ }^{1}$ In Brazil, mortality rates follow the global declining trend, but CVDs continue to be the leading cause of death with around $30 \%$ of annual deaths and 286 deaths per 100,000 people. ${ }^{2}$ In 2012, CVDs alone accounted for $8.3 \%$ of total hospitalizations, and $18.6 \%$ of all reimbursement from the Brazilian National Unified Health System (SUS - Sistema Único de Saúde) to hospitals. ${ }^{3}$

Economic and social changes which have occurred in Brazil in the last decades, besides contributing to a rapid demographic transition, also exposed the population to the risk of developing CVDs. ${ }^{2-3}$ Among the risk factors for CVDs are: smoking, alcoholism, physical inactivity and inadequate diet. Despite the decreasing tendency of heavy and passive smokers and increased physical activity in the Brazilian population, overweight and obesity have increased in recent years, ${ }^{3}$ leading to the presence of important risk factors for the occurrence of CVDs.

The burden of CVD disproportionately affects the poor population ${ }^{2}$ who less frequently adopt protective behaviors. ${ }^{3}$ Moreover, the financial impact on deaths attributable to cardiovascular diseases, drug expenditures, interventions and above all hospital admissions, is a challenge to world economic development. Such a reality threatens the progress of the Millennium Development Goals (MDGs) and of Sustainable Development Goals (SDGs), which include poverty reduction, social equity, economic stability, human security and the environment. ${ }^{4}$

In the last two decades, Brazil implemented policies which expanded the focus on CVD prevention, health promotion and intersectoral actions in detriment of individualized and traditional healthcare actions. ${ }^{2}$ For SUS, Primary Health Care (PHC or Atenção Primária à Saúde in Brazil) must guarantee access to actions that prevent health problems, and when these actions reveal good quality they reflect a decrease in hospitalization rates for various causes, ${ }^{5}$ including for CVD. ${ }^{6}$

Similar to other countries, Brazil has drawn up a list of diseases and disorders which are considered avoidable through PHC actions. Being health conditions that can be mediated, the occurrence of these diseases and comorbidities becomes an indirect indicator of healthcare effectiveness developed in PHC. On the Brazilian list, CVDs include systemic arterial hypertension (SAH), heart failure (HF), cerebrovascular disease (CbVD) and angina. ${ }^{7}$

As a way of evaluating PHC, a study carried out in Brazil between 1998 and 2009 on hospital admissions revealed a decline in $\mathrm{HF}$ and CbVD, and stability of SAH for both genders, as well as an increase in admissions of men and stability in women for angina. ${ }^{6}$ In the state of Goiás, hospitalization rates for cardiovascular conditions sensitive to primary care (CCSPC) decreased according to gender and age. ${ }^{8}$ This tendency was also identified 
in the state of Paraná, from 2000 to 2011, for SAH, HF and CbVD. ${ }^{9}$

CVD hospitalizations have been little used as an indicator of healthcare system performance. Therefore, studies on conditions sensitive to primary care (CSPC) are necessary, especially those focused on regions and municipalities in Brazil. This is because frequent and localized surveys can add detailed information and contribute to municipal and regional managers to assess the effectiveness, quality, and adequacy of the healthcare network focused on CVDs.

From the aforementioned, the objective of this study was to analyze the trend of hospitalizations for cardiovascular conditions sensitive to primary healthcare from 2000 to 2011. This is based on the premise that if there is access, quality and resolution in PHC, diseases can be prevented, or if present, they can be treated and controlled, thus avoiding complications and the need for hospitalization.

\section{METHOD}

This is an ecological time series study realized in the municipality of Maringá, Paraná, Brazil, with residents of 35 to 74 years of age in the years 2000 to 2011, classified as cardiovascular conditions sensitive to PHC. The coefficients were constructed from information contained in the Authorization for Hospital Admittance (Autorização de Internação Hospitalar - AIH), a basic document of the SUS Hospital Information System (SIH-SUS) and from the population data of the Brazilian Institute of Geography and Statistics (Instituto Brasileiro de Geografia e Estatística - IBGE), made available on the electronic website of the Ministry of Health Informatics Department (Departamento de Informatica do Sistema Único de Saúde - DATASUS).

Files from the SIH-SUS were selected according to the place of residence and type $1 \mathrm{AIH}$. Subsequently, hospitalizations by SAH (ICD-10: I10 and I11), angina (ICD-10: I20), HF (ICD-10: I50 and J81) and CbVD (ICD-10: I63, I67, I69, G45 and G46) were selected based on the Brazilian List of CSPC, ${ }^{7}$ by the stratified age groups of 35 to 54 years and 55 to 74 years, and analyzed according to the main diagnosis of hospitalization and gender.

CVD hospitalization rates were analyzed according to: a) the number and proportion of hospitalizations for CSPC and CCSPC in relation to the total hospitalizations (except births); B) hospitalization rates per 10,000 inhabitants according to gender, age, cardiovascular cause and total hospitalizations for all causes, CSPC and CCSPC, and c) the relative differences of the rates were calculated between triennium (period of 3 years) points and the extreme triennium of the studied period.

In order to analyze trends in hospitalization rates for CVDs, the polynomial regression model was used where hospitalization rates represent the dependent variable $(Y)$, and the study years represent the independent variable $(X)$. In order to avoid autocorrelation between the regression terms, the independent variable was transformed into a year-centered variable, meaning the year minus the midpoint of the historical series, which in this study was $2005 .{ }^{10} \mathrm{Next}$, dispersion diagrams between hospitalization rates and study years were constructed in order to visualize the function best expressing the relation between the indicators and to facilitate the choice of the polynomial order. ${ }^{10}$ In the subsequent phase, second grade and third grade simple linear regression models were tested. The best model was considered the one which presented the highest statistical significance $(p<0.05)$, residuals without vices and coefficient of determination $\left(r^{2}\right)$, which was used as a precision measure for values close to 1 . In the occurrence of statistically similar models, we opted for the parsimony principle, considering the simplest model. ${ }^{10}$ Variations in the series were smoothed by moving average centered on three successive averages, so that the annual rates corresponded to the arithmetic average of the rates of the previous year, of the year itself, and of the following year.

For comparing the period, hospitalization rates were grouped into triennium and the relative difference was calculated between the extreme triennium. Microsoft Office Excel software was used for database tabulation and rates calculation, and the Statistical Package for the Social Sciences (SPSS) was used for trends analysis. The study was evaluated and exempted from analysis by the Research Ethics Committee (Opinion 039 / 2012), as it is an investigation using publicly accessible secondary data.

\section{RESULTS}

Table 1 shows an increase in the number of hospitalizations from all causes, and a decline in hospitalizations by CSPC (-42.5\%) and CCSPC (-42.1\%) in residents aged 35-74 years. The proportion of hospitalizations for all CSAPs, and specifically CC$\mathrm{SPC}$, in relation to hospitalizations for all causes also decreased (-52.6\% and $-52.3 \%$, respectively).

Table 1 also shows a decline in hospitalization rates for CSPC $\left(r^{2}=0.9, p<0.001\right)$ and for CCSPC 
$\left(r^{2}=0.9, p<0.001\right)$. For CCSPC admissions (with the exception of angina whose rates remained stable), a decreasing trend in hospitalization rates was observed for SAH, HF and CbVD. HF had the highest average hospitalization rate (40.4 admissions per 10,000 inhabitants) and the highest rate of decline
(-3.8 admissions per 10,000 inhabitants per year). $\mathrm{SAH}$ and $\mathrm{CbVDs}$ presented similar average rates of hospitalization (12.4 and 12.9/10,000, respectively), as well as declining rates $(-1.0$ and -0.7 , respectively, on average, per year) (Table 2).

Table 1 - Hospitalizations for all causes, for conditions sensitive to primary care and for cardiovascular conditions sensitive to primary care. Maringá, PR, Brazil, 2000 to 2011.

\begin{tabular}{lrrrrrrrrrrrrr}
\hline & $\mathbf{2 0 0 0}$ & $\mathbf{2 0 0 1}$ & $\mathbf{2 0 0 2}$ & $\mathbf{2 0 0 3}$ & $\mathbf{2 0 0 4}$ & $\mathbf{2 0 0 5}$ & $\mathbf{2 0 0 6}$ & $\mathbf{2 0 0 7}$ & $\mathbf{2 0 0 8}$ & $\mathbf{2 0 0 9}$ & $\mathbf{2 0 1 0}$ & $\mathbf{2 0 1 1}$ & Rel. dif. \\
\hline All causes (n) & 8209 & 8170 & 7892 & 8358 & 7891 & 8354 & 8262 & 10414 & 9178 & 10076 & 10963 & 9968 & 21.4 \\
CSPC $^{\dagger}(\mathrm{n})$ & 2758 & 2269 & 1844 & 2245 & 1998 & 1890 & 1816 & 2351 & 1750 & 1827 & 1949 & 1585 & -42.5 \\
CCSPC $^{\ddagger}(\mathrm{n})$ & 1412 & 1223 & 941 & 1202 & 1078 & 815 & 740 & 960 & 800 & 973 & 958 & 818 & -42.1 \\
CSPC/All (\%) & 33.6 & 27.8 & 23.4 & 26.9 & 25.3 & 22.6 & 22.1 & 22.6 & 19.1 & 18.1 & 17.8 & 15.9 & -52.6 \\
CCSPC/All (\%) & 17.2 & 15.0 & 11.9 & 14.4 & 13.7 & 9.8 & 9.0 & 9.2 & 8.7 & 9.7 & 8.7 & 8.2 & -52.3 \\
CCSPC/CSPC (\%) & 51.2 & 53.9 & 51.0 & 53.5 & 54.0 & 43.1 & 40.7 & 40.8 & 45.7 & 53.3 & 49.2 & 51.6 & 0.8 \\
\hline
\end{tabular}

"Rel. dif. - Relative difference between the extreme years (2000 and 2011); ${ }^{\dagger} \mathrm{CSPC}$ - Conditions sensitive to primary care; ${ }^{\circ} \mathrm{CCSPC}$ - Cardiovascular conditions sensitive to primary care.

Table 2 - Hospitalization rates and trend analysis of hospitalization rates for all causes, for conditions sensitive to primary care and for cardiovascular conditions sensitive to primary care. Maringá, PR, Brazil, 2000 to 2011.

\begin{tabular}{lrrrrrrrrrrrrrrrr}
\hline & $\mathbf{2 0 0 0}$ & $\mathbf{2 0 0 1}$ & $\mathbf{2 0 0 2}$ & $\mathbf{2 0 0 3}$ & $\mathbf{2 0 0 4}$ & $\mathbf{2 0 0 5}$ & $\mathbf{2 0 0 6}$ & $\mathbf{2 0 0 7}$ & $\mathbf{2 0 0 8}$ & $\mathbf{2 0 0 9}$ & $\mathbf{2 0 1 0}$ & $\mathbf{2 0 1 1}$ & Model & $\mathbf{R}^{\mathbf{2}}$ & $p$ & Trend \\
\hline Todas & 756.4 & 738.2 & 702.5 & 732.4 & 680.9 & 696.7 & 677.4 & 750.5 & 649.6 & 694.9 & 712.9 & 638.8 & $\mathrm{y}=704.1-4.6 \mathrm{x}^{*}$ & 0.7 & 0.002 & Decreasing \\
CSPC $^{\ddagger}$ & 254.1 & 205.0 & 164.1 & 196.7 & 172.4 & 157.6 & 148.9 & 169.4 & 123.9 & 126 & 126.7 & 101.6 & $\mathrm{y}=164.5-9.2 \mathrm{x}^{*}$ & 0.9 & $<0.001$ & Decreasing \\
CCSPC $^{\S}$ & 130.1 & 110.5 & 83.8 & 105.3 & 93.0 & 68.0 & 60.7 & 69.2 & 56.6 & 67.1 & 62.3 & 52.4 & $\mathrm{y}=80.8-5.6 \mathrm{x}^{*}$ & 0.9 & $<0.001$ & Decreasing \\
HF।I $^{*}$ & 72.2 & 62.3 & 37.1 & 50.0 & 51.9 & 43.6 & 31.7 & 29.5 & 23.8 & 28.9 & 25.2 & 17.3 & $\mathrm{y}=40.4-3.8 \mathrm{x}^{*}$ & 0.9 & $<0.001$ & Decreasing \\
CbVD $^{\star}$ & 28.3 & 21.7 & 14.4 & 19.7 & 12.2 & 7.9 & 11.7 & 18.2 & 12.5 & 15.7 & 17.9 & 13.5 & $\mathrm{y}=12.9-0.7+0.3 \mathrm{x}^{\dagger}$ & 0.8 & 0.002 & Decreasing \\
SAH $^{* *}$ & 24.5 & 20.3 & 14.4 & 12.9 & 11.8 & 8.3 & 11.2 & 12.2 & 9.7 & 8.6 & 8.3 & 9.4 & $\mathrm{y}=12.4-1.0 \mathrm{x}^{*}$ & 0.7 & 0.001 & Decreasing \\
Angina & 5.1 & 6.1 & 17.8 & 22.7 & 17.1 & 8.2 & 6.1 & 9.3 & 10.6 & 13.9 & 10.9 & 12.2 & $\mathrm{y}=12.5-0.4 \mathrm{x}^{*}$ & 0.1 & 0.338 & Stable \\
\hline
\end{tabular}

"Linear Regression Model; ${ }^{\dagger}$ Second order model; ${ }^{\ddagger} \mathrm{CSPC}$ - Conditions sensitive to primary care; ${ }^{\S} \mathrm{CCSPC}$ - Cardiovascular conditions sensitive to primary care; ${ }^{\prime \prime} \mathrm{HF}$ - Heart failure; ${ }^{\circ} \mathrm{CbVD}$ - Cerebrovascular diseases; **SAH - Systemic arterial hypertension.

The hospitalization rates for angina, HF and $\mathrm{CbVD}$ were higher in relation to men. Regarding angina, despite stability, hospitalization rates for men increased by $47.4 \%$ between the extreme trien- nials. Hospitalization rates for HF declined $62.2 \%$ for women and $55.5 \%$ for men. The decrease was lower for cerebrovascular diseases, being $32.1 \%$ for men and $16.1 \%$ for women (Figure 1). 


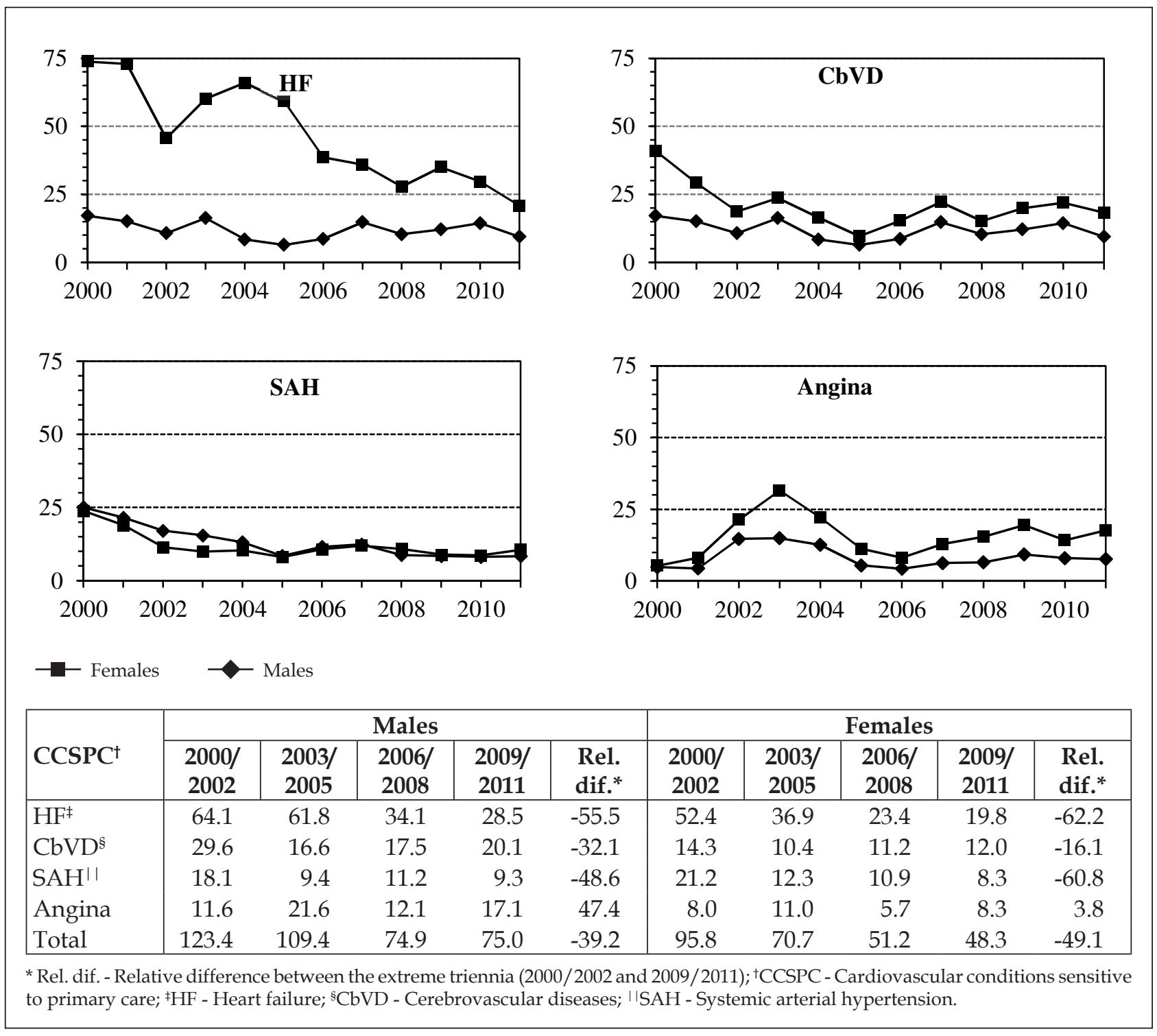

Figure 1 - Trend of hospitalization rates for cardiovascular conditions sensitive to primary care, by gender. Maringá, PR, Brazil, 2000 to 2011.

Hospitalization rates were highest in the age group of 55 to 74 years, but it was also at that age that the largest declines were found, mainly in relation to women by $\mathrm{CbVD}(-27.3 \%)$, and for men both by
HF (-60.2\%) and by CbVD (-42.1\%). For residents 35 to 54 years old, an increase in angina was observed in both genders $(100.0 \%$ and $55.6 \%$, respectively for men and women) (Figures 2 and 3). 


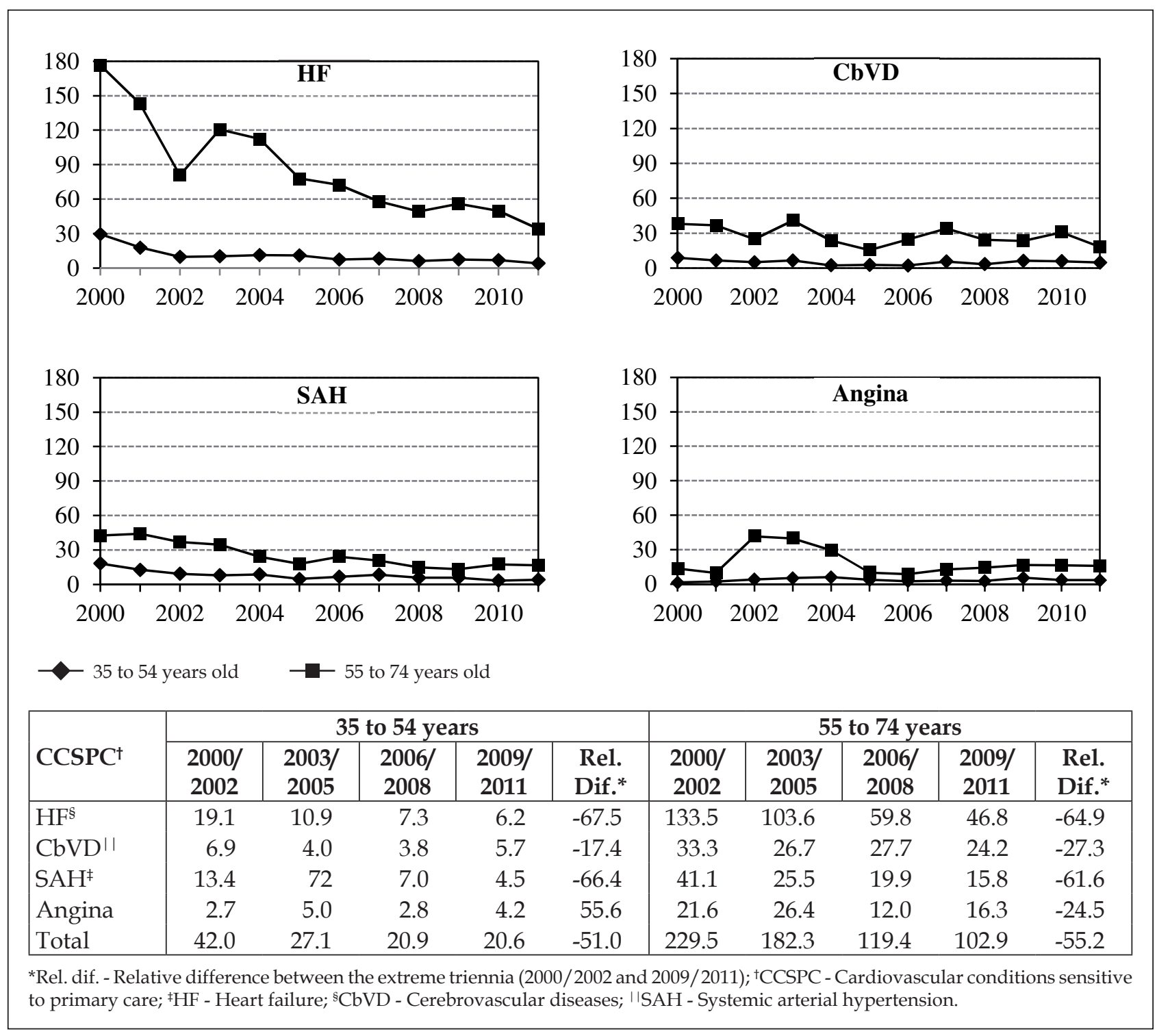

Figure 2 - Trend of hospitalization rates for cardiovascular conditions sensitive to primary care in females, according to age. Maringá, PR, Brazil, 2000 to 2011. 


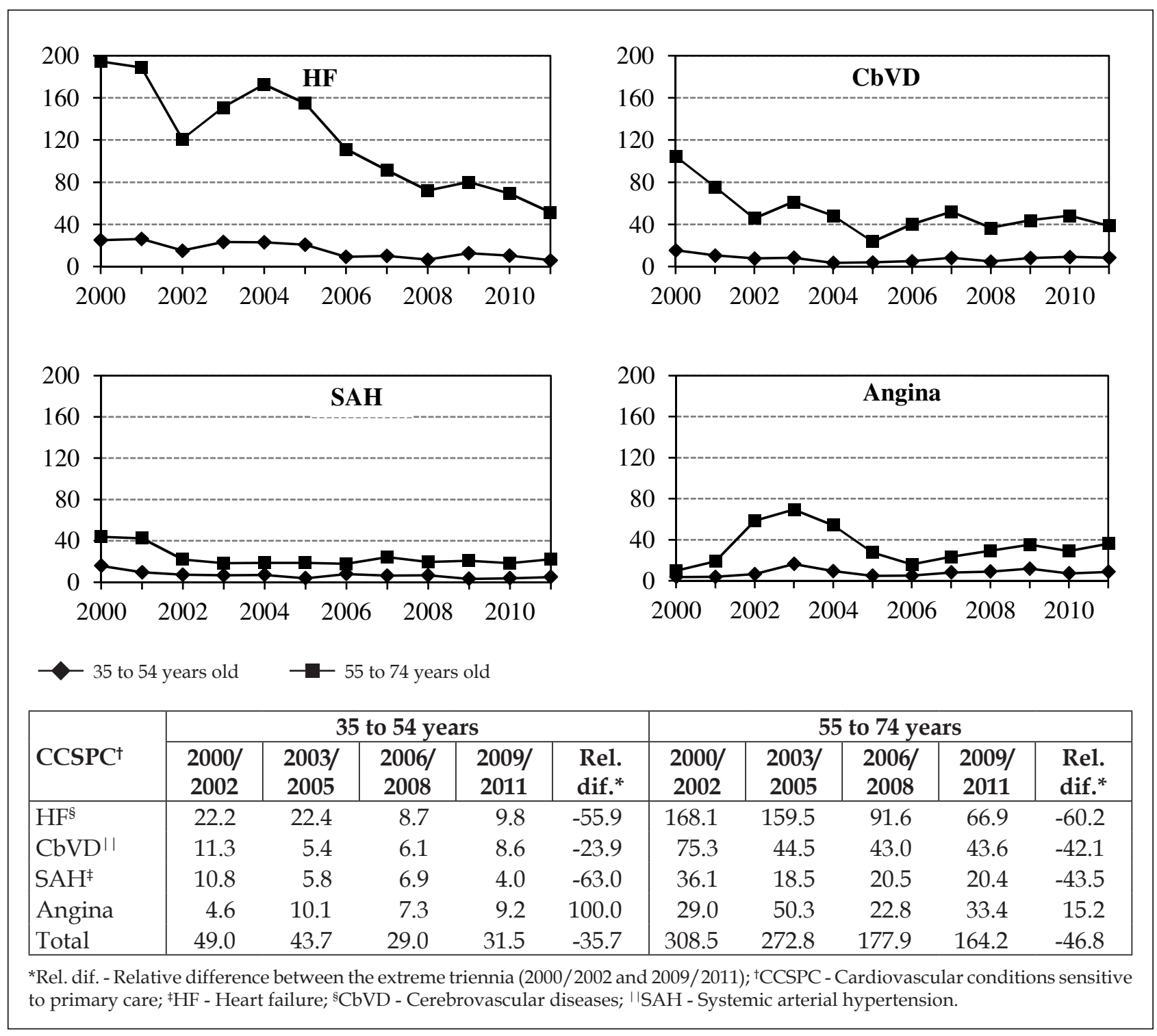

Figure 3 - Trend of hospitalization rates for cardiovascular conditions sensitive to primary care in males, according to age. Maringá, PR, Brazil, 2000 to 2011

\section{DISCUSSION}

The trend of hospitalization rates for CCSPC was decreasing and follows the pattern already described in the literature. ${ }^{6,8-9}$ The impact of public health policies in Brazil has already been associated with lower hospitalization rates by CSPC, especially in regions with greater coverage by the Family Health Strategy (Estratégia Saúde da Familia - ESF). ${ }^{5}$ In Maringá, the ESF presented stability in its population coverage in the period from 2000 to 2011, however it maintained itself above the state of Paraná and Brazil. ${ }^{11}$ These data are relevant when considering that CVD patients may require greater organization in primary care, public health and social programs.
Thus, clinical guidelines and comprehensive management of risk factors can contribute to improve the quality of life of people with CVDs and reduce the number of interventions that result in hospitalization. ${ }^{12}$ Therefore, early detection of individuals at high risk of CVD is vital in primary prevention, ${ }^{13}$ and guidelines that emphasize community actions and the protagonist role of PHC services are necessary because in addition to identification, studying changes in the epidemiological profile of CVDs can be a way to monitor the effect of policies on health promotion and disease prevention.

In addition to PHC access and its quality, it is considered that other aspects may influence hospitalization rates, including the improvement of the 
socio-economic conditions of the population in the last decade, access to private or specialized health services, an unhealthy lifestyle, conflicting medical procedures for the same clinical situation, and greater use of preventive care by the population. ${ }^{14}$

In turn, the increase in life expectancy and prevalence of CVDs, their detection, prevention, treatment and planning of preventive actions has been recognized in Brazil. Currently, the Strategic Action Plan to Combat Non-Communicable Diseases in Brazil for 2011-2022 (Plano de Ações Estratégicas para o Enfrentamento das DCNT) is in effect, which aims to deploy and develop effective public policies for controlling and preventing chronic diseases and their risk factors, in addition to strengthening actions in healthcare service. ${ }^{15}$ The purpose of this plan is to complement and rearrange actions already being conducted by the Ministry of Health: treatment protocols and CVD prevention, free or low-cost access to medicines for hypertension and diabetes mellitus, and encouraging physical activity. ${ }^{3}$

Other strategies directed at the main risk factors that incorporate public policies for CVD prevention and control are multisectoral anti-tobacco actions, ${ }^{2}$ the national obesity prevention plan centered on social and environmental causes through healthy eating, ${ }^{16}$ and increased government stimulus with project funding to reduce structural barriers to access physical activity. ${ }^{17}$

In this sense and according to the National Policy on Health Promotion (Politica Nacional de Promoção da Saúde - PNPS) guidelines, the Healthy Maringá Program (Programa Maringá Saudável) was implemented in the municipality in the last decade. It has developed actions provided by the Global Strategy on Healthy Eating, Physical Activity and Health, by promoting healthy habits and controlling risk factors through a set of actions that involve the areas of physical activity, healthy eating and smoking control; highlighting gyms for older adults with 52 units implemented in the municipality and with several projects related to this pioneering initiative in Brazil. ${ }^{18}$

The PHC approach on risk factors for CVDs, support for health self-management, longitudinal follow-up by health teams, empowerment and autonomy, ${ }^{15}$ may be reflecting a change in the PHC care standards in Maringá and in the population's behavior in relation to this disease. In Brazil, data on surveillance of risk factors point to a reduction in smoking and an increase in physical activity. ${ }^{3}$ These results together with the greater knowledge about the risk factors and improving the socioeconomic conditions of the population reflect in reduced hospitalizations for CVD.

Regarding HF, the trend of hospitalizations decreased during the period. Despite being the main cause of hospitalization for CCSPC and representing one of the major causes of hospitalization in Brazil, ${ }^{3}$ HF obtained the largest decrease for both genders. Furthermore, it reached very similar rates to other CCSPC in 2011, especially in relation to men. Regarding the age group, this condition showed a greater decrease in the population of 35 to 54 years old, with similar rates to the remaining causes in both genders.

$\mathrm{HF}$ is a complex condition and requires competence in the way it is managed, from its diagnosis and identification of comorbidities, to understanding its treatment, and identifying and managing patients with low risk HF becomes essential to avoid hospitalizations. ${ }^{19}$ In addition, difficulty in outpatient control of the disease, overestimation of its severity and premature hospitalizations become major causes for hospitalization as its main treatment, ${ }^{20}$ thus, the lack of patient risk stratification and evidence-based clinical principles make admissions an exclusive practice. In this sense, PHC professionals play an important role for patients with this disorder, requiring individual and collective interventions for its control.

The decline in admissions by CbVD was identified in both genders, and although rates were higher in men, the relative decline in males was also higher, especially among the age group of 55 to 74 years. A similar result was found in Rio de Janeiro in the 2000 s, with a $48.7 \%$ reduction in hospitalizations of older adults, and a higher risk of hospitalization among males. ${ }^{21}$ This decrease in hospitalization rates for CbVD may be positive, since the results have shown a decreasing trend in mortality by CbVD between 1980 and 2012 in Brazil (-48.05\%) and in the South region $(-55.49 \%),{ }^{22}$ and high rates in the macro-regional health of Maringá (23.3 per 10,000 deaths) in relation to the other regions in the state of Paraná in 2007. ${ }^{23}$

Similarly to CbVD, hospitalizations for $\mathrm{SAH}$ decreased during the study period, with similar average rates and decline speed. This result is in agreement with data from a systematic review on SAH in Brazil of more than 40 studies and 120,000 individuals, which saw a trend of progressive decline from $36.1 \%$ in the 1980 s to $32.9 \%$ in the 1990 s, and to $28.7 \%$ in the subsequent decade. This prevalence did not differ between the genders or regions of the country. ${ }^{24}$ In the United States, a study regard- 
ing SAH hospitalization rates from 1980 to 2007 in adults aged 35 years or older found an increase from $1.74 \%$ to $2.06 \%$ in men, and $2.0 \%$ to $2.09 \%$ in women. This study also pointed to some factors as possible explanations for these results, namely: disparities in the prevalence of $\mathrm{SAH}$, inadequate care including medication and lifestyle issues, socioeconomic variables such as income and education level, geographical barriers and the presence of comorbidities. ${ }^{25}$

In addition to improving treatment, primary prevention and early diagnosis of hypertension reduces the use of hospital beds, ${ }^{19}$ and the success of these efforts in controlling SAH are able to influence other sensitive cardiovascular conditions as this condition is a risk factor for other chronic diseases.

In the present study, the outcome for the trend of hospitalizations for angina was stable. There was a difference between men and women in gender analysis, with growth rates in the male gender, mainly between 35 and 54 years. It is possible that progress in treating coronary artery disease in primary and secondary care in Maringá may have contributed to this trend of stability in hospitalizations for angina, with improved access to medical services, interventions used for chronic and acute conditions ranging from reperfusion to specific medication and risk factor control.

Studies in the U.S. have identified a decline in hospitalization rates for angina, ${ }^{12,26}$ which may be due to a decrease in the disease prevalence ${ }^{26}$ based on improving risk factors, diagnostic quality, increased use of cardiac revascularization and use of endocrine regulators, outpatient treatment for chest pain, changes in the form of hospital reimbursement and disease/illness coding, in addition to a more aggressive disease diagnosis practice, mainly for atherosclerosis. ${ }^{12}$

Data on angina in Maringá follow the same pattern as those found for the State of Paraná. ${ }^{9}$ Factors that may have contributed to reduced hospitalization rates are not restricted to $\mathrm{PHC}$ alone, but also to outpatient healthcare, including improved quality in the organization of health services to guarantee access, implementing the approach of controlling risk factors for the self-care of CVDs, evolving and establishing pecialized medical centers for therapeutic interventions in acute and chronic events of heart and vascular diseases, in addition to emergency and emergency support from implementing the mobile emergency service (SAMU) and hospital bed regulating center. This advance in the structure and process for treating coronary artery disease may have contributed to maintaining the hospitalization rates for angina in Maringá, as this condition requires therapeutic interventions used for acute and chronic diseases.

Hospitalization rates differed between genders. For men, hospitalizations for angina, HF and CbVD were higher, whereas hospitalizations for $\mathrm{SAH}$ were more frequent in women at the beginning of the series, and in men at the end. The higher hospitalization risk for men was also observed in studies in Rio de Janeiro ${ }^{21}$ and Paraná, ${ }^{9}$ unlike Goiás, where female rates were higher. ${ }^{8}$ These differences in gender rates could be explained by the way each gender approaches their health care and lifestyle patterns.

On the other hand, an increase in hospitalizations with increasing age parallels an increase in comorbidities over the course of life. However, despite the high rates, major declines occurred in the older age group, especially in hospitalizations for $\mathrm{HF}$ and SAH in both genders, and cerebrovascular diseases in men, thus suggesting a PHC approach to health promotion and controlling risk factors and symptoms of these cardiovascular causes. ${ }^{21}$

The results point to a positive outlook for Maringá due to its maintenance of ESF coverage, and despite the results being localized, they may be plausible for other realities that invest in the ESF. Other factors may influence outcomes such as medical practice and socioeconomic aspects of the population. Therefore, only admissions for sensitive conditions are not sufficient in assessing PHC; however, they indirectly allow for assessing the healthcare network which should be focusing on the comprehensive care of patients with CVD. ${ }^{27}$

This comprehensiveness is related to the quality of actions undertaken by PHC. In Brazil, a recent study that calculated the index of health priorities presented important results for health interventions, mainly because they concern PHC and CVD. It reported that $\mathrm{SAH}$, a sedentary lifestyle, blood pressure screening, hypercholesterolemia, smoking and excessive alcohol consumption, in addition to overweight and obesity have the greatest impact on the health of Brazilians today. ${ }^{28}$ All are factors having a high impact on CVDs and subject to actions by PHC.

Indirect performance evaluation of the health system by CSPCs has been portrayed in recent studies. $^{7-9.21}$ Political-administrative mechanisms based on determinations of the World Health Organization (WHO), among them the Strategic Action Plan to Combat Non-Communicable Diseases in Brazil 
(2011-2022), ${ }^{15}$ and the Public Health Action Organizational Contract (COAP) represent the concept of preventability to more than specific groups (children and young people), ${ }^{21}$ as is the case for CVDs. ${ }^{9}$

PHC actions on risk factors for CVDs and the use of PHC-sensitive hospitalizations as an indicator of healthcare system performance may trigger administrative actions, such as the intent of Washington State to punish hospitals with high rates of hospitalizations and avoidable emergencies. The use of this type of rule (criticized even in the United States ${ }^{29}$ should be viewed with caution, especially in countries with universal health systems, since hospitalization for CSPC is conditioned by aspects which are not controlled by PHC, and the fact that many diseases are managed in primary care settings does not mean that care will always be available or will be of good quality.

The quality of hospitalization information in the SIH-SUS may be a limitation of this study, and may be affected by errors in the classification and use of ICD-10. The codification of diagnoses and procedures in the $\mathrm{AIH}$ which present greater financial value by the hospitals may end up over or underestimating hospitalizations by CVDs.

\section{CONCLUSION}

The results of the study showed a declining trend in hospitalizations for CCSPC (PHC-sensitive cardiovascular conditions) in residents of the Maringá municipality, Paraná, Brazil, from 2000 to 2011, when analyzed by the main hospitalization diagnosis, gender and age; aside from hospitalizations for angina, which presented a stable trend. Residents aged 55-74 years had the highest rates of CCSPC hospitalization and higher percentages of decline. In the cause analysis, the decline in HF was more pronounced than the other conditions in both genders. These results confirm the need to eliminate differences in health between genders and age groups, especially for angina, to reduce the risk for CVD, and implement actions to prevent hospitalizations for these conditions within PHC.

Studies of hospital admissions are an important tool for monitoring the occurrence of cardiovascular diseases and their complications. The use of SIH-SUS as a data source can contribute to its strengthening/improvement, since this information system is considered an important tool for understanding the health situation of the SUS user population. Likewise, analyzing admissions for sensitive conditions constitutes an indirect and complementary evaluation measure of the primary level of healthcare, capable of providing subsidies to managers (such as the results of this study) for hospitalizations related to males, hospitalizations for angina, and hospitalizations in residents of 35 to 74 years of age.

In addition to the influence of increased coverage and population access to $\mathrm{PHC}$, several other factors may have contributed to the positive results presented in this study, such as the change in the population's lifestyle, adherence to treating chronic diseases, increases in education levels and income of the population, among others, thus reducing risk factors for cardiovascular diseases.

In this sense, even with the influence of external factors to PHC actions which impact CVD hospitalizations, this level of care is essential for avoiding hospitalization, as demonstrated by the sensitivity conditions indicator. Future research capable of isolating the effect of PHC on CVD hospitalizations will be needed, in addition to studies that fully understand the reasons behind angina stability.

\section{REFERENCES}

1. World Health Organization (WHO). Global atlas on cardiovascular disease prevention and control [Internet]. Genebra: WHO; 2011 [cited 2015 May 19]. Available from: http://www.who.int/ cardiovascular_diseases/publications/atlas_cvd/en/

2. Schmidt MA, Duncan BB, Silva GA, Menezes AM, Monteiro CA, Barreto SM, et al. Chronic noncommunicable diseases in Brazil: burden and current challenges. Lancet. 2011 Jun; 377 (9781):1949-61.

3. Ribeiro ALP, Duncan BB, Brant LCC, Lotufo PA, Mill JG, Barreto SM. Cardiovascular health in Brazil: trends and perspectives. Circulation. 2016 Jan; 133(4):422-33.

4. United Nations (UN). Transforming our world: the 2030 agenda for sustentable development. New York (US): UM; 2015.

5. Macinko J, Oliveira VB, Turci MA, Guanais FC, Bonolo $\mathrm{PF}$, Lima-Costa MF. The influence of primary care and hospital supply on ambulatory care-sensitive hospitalizations among adults in Brazil, 1999-2007. Am J Public Health [Internet]. 2011 Out [cited 2015 Apr 9]; 101(10):1963-70. Available from: http://www. ncbi.nlm.nih.gov/pubmed/21330584

6. Boing AF, Vicenzi RB, Magajewski F, Boing AC, Moretti-Pires RO, Peres HG, et al. Redução das internações por condições sensíveis à atenção primária no Brasil entre 1998-2009. Rev Saúde Pública. 2012 Abr; 46(2):359-66.

7. Alfradique ME, Bonolo PF, Dourado I, Lima-Costa MF, Macinko J, Mendonça CS, et al. Internações por 
condições sensíveis à atenção primária: a construção da lista brasileira como ferramenta para medir o desempenho do sistema de saúde (Projeto ICSAP Brasil). Cad Saúde Pública. 2009 Jun; 25(6):1337-49.

8. Batista SRR, Jardim PCBV, Sousa ALL, Salgado CM. Hospitalizações por condições cardiovasculares sensíveis à atenção primária em municípios goianos. Rev Saúde Pública. 2012 Jan; 46(1): 34-42.

9. Lentsck MH, Latorre MRDO, Mathias TAF. Tendência das internações por doenças cardiovasculares sensíveis à atenção primária. Rev Bras Epidemiol. 2015; 18(2):372-84.

10. Latorre MRDO, Cardoso MRA. Análise de séries temporais em epidemiologia: uma introdução sobre os aspectos metodológicos. Rev Bras Epidemiol. 2001; 4(3):145-52.

11. Ministério da Saúde (BR). Histórico de cobertura saúde da família [Internet]. Brasília (DF): MS 2014 [cited 2014 Apr 21]. Available from: http:/ / dab.saude. gov.br/portaldab/historico_cobertura_sf.php

12. Will JC, Valderrama AL, Yoon PW. Preventable hospitalizations and emergency department visits for angina, United States, 1995-2010. Prev Chronic Dis [Internet]. 2013 Jul [cited 2015 Mar 9]; 10:120322. Available from: http://www.cdc.gov/pcd/ issues/2013/12_0322.htm

13. Van der Hoeven NV, Niessen MAJ, Stroes ESG, Burdorf L, Kraaijenhagen RA, Van den Born BH. A six question screen to facilitate primary cardiovascular disease prevention. BMC Cardiovasc Disord. [Internet]. 2015[cited 2016 Jul 16]; 15:140. Available from: http:/ / www.ncbi.nlm.nih.gov/pmc/articles/ PMC4628315/

14. Hossain MM, Laditka JN. Using hospitalization for ambulatory care sensitive conditions to measure access to primary health care: an application of spatial structural equation modeling. Int J Health Geogr [Internet]. 2009 Ago [cited 2015 Apr 8]; 8(51). Available from: http:/ / www.ncbi.nlm.nih.gov/ pubmed/19715587

15. Malta DC, Neto OLM, Junior JBS Apresentação do plano de ações estratégicas para o enfrentamento das doenças crônicas não transmissíveis no Brasil, 2011 a 2022. Epidemiol Serv Saúde. 2011 Out-Dez; 20(4):425-38.

16. Jaime PC, da Silva AC, Gentil PC, Claro RM, Monteiro CA. Brazilian obesity prevention and control initiatives. Obes Rev [intenet]. 2013; [cited 2016 Jul 12]; 14(suppl2):88-95. Available from: http:/ / onlinelibrary. wiley.com/doi/10.1111/obr.12101/abstract; jsessionid=5D7227F42C96588250A8FA1A218CD33A. f01t04

17. Parra DC, Hoehner CM, Hallal PC, Reis RS, Simoes EJ, Malta DC, et al. Scaling up of physical activity interventions in Brazil: how partnerships and research evidence contributed to policy action. Glob Health Promot [Internet]. 2013; [cited 2016 Jul 12]; 20: 5-12. Available from: http:/ / www.ncbi.nlm.nih.gov/pmc/ articles/PMC3917705/

18. Secretaria Municipal de Saúde de Maringá (BR). Plano Municipal de Saúde de Maringá-PR 2014/2017. Maringá (PR): Secretaria Municipal de Saúde; 2013.

19. Will JC, Yoon PW. Preventable hospitalizations for hypertension: establishing a baseline for monitoring racial differences in rates. Prev Chronic Dis [Internet]. 2013 Fev [cited 2015 Mar 12]; 10: 120165. Available from: http:/ / www.cdc.gov/pcd/issues/2013/12_0165.htm

20. Collins SP, Lindsell CJ, Jenkins CA, Harrell FE, Fermann GJ, Miller KF, et al. Risk stratification in acute heart failure: rationale and design of the STRATIFY and DECIDE studies. Am Heart J [Internet]. 2012 [cited 2015 Apr 12]; 164 (6):825-34. Available from: http:/ / www.ncbi.nlm.nih.gov/pmc/articles / PMC3511776/

21. Marques AP, Montilla DER, Almeida WS, Andrade CLT. Internação de idosos por condições sensíveis à atenção primária à saúde. Rev Saúde Pública. 2014; 48(5):817-26.

22. Guimarães RM, Andrade SSCA, Machado EL, Bahia CA, Oliveira MM, Jacques FVL. Diferenças regionais na transição da mortalidade por doenças cardiovasculares no Brasil, 1980 a 2012. Rev Panam Salud Publica [Internet]. 2015 Fev [cited 2016 Jul 14]; 37(2):83-9. Available from: http:/ / www.scielosp.org/ pdf/rpsp/v37n2/a03v37n2.pdf

23. Furukawa TS, Mathias TAF, Marcon SS. Mortalidade por doenças cerebrovasculares por residência e local de ocorrência do óbito: Paraná, Brasil, 2007. Cad Saúde Pública. 2011 Fev; 27(2):327-34.

24. Picon RV, Fuchs FD, Moreira LB, Riegel G, Fuchs SC. Trends in prevalence of hypertension in Brazil: a systematic review with meta-analysis. PLoS One [Internet]. 2012 [cited 2016 Jul 12]; 7:e48255. Available from: http://journals.plos.org/plosone/ article?id=10.1371/journal.pone.0048255

25. Liu L, An Y, Chen M, Liu Z, Hu X, Chou E, et al. Trends in the prevalence of hospitalization attributable to hypertensive diseases among United States adults aged 35 and older from 1980 to 2007. Am J Cardiol. 2013 Sep; 112(5):694-9.

26. Will JC, Yuan K, Ford E. National trends in the prevalence and medical history af angina: 1988 to 2012. Cir Cardiovasc Qual Outcomes [Internet]. 2014 May [cited 2015 Apr 8]; 7(3):407-13. Available from: http:/ / www.ncbi.nlm.nih.gov/pmc/articles/ PMC4366681/

27. Rehem TCMSB, Ciosak SI, Egry EY. Internações por condições sensíveis à atenção primária no hospital 
geral de uma microrregião de saúde do município de São Paulo, Brasil. Texto Contexto Enferm [Internet]. 2012 Jul-Set [cited 2015 May 18]; 21(3):535-42. Available from: http:/ / www.scielo.br/scielo.php?pid=S010407072012000300007\&script=sci_arttext

28. Simões EJ, Bouras A, Cortez-Escalante JJ, Malta DC, Porto DL, Mokdad AH, et al. A priority health index identifies the top six priority risk and related factors for non-communicable diseases in Brazilian cities. BMC Public Health [Internet]. 2015 Mai [cited 2016 Jul 14]; 15(443). Available from: http:/ / bmcpublichealth.biomedcentral.com/articles/10.1186/s12889-015-1787-1

29. Kellermann AL, Weinick RM. Emergency departments, medicaid costs, and access to primary care understanding the link. N Engl J Med. 2012 Jun; 366 (23):2141-3. 